\title{
La mujer digital
}

Tatiana poggi

Universidad de Alicante, Departamento de Expresión Gráfica y Cartografía, Escuela Politécnica Superior (Arquitectura), Alicante, España.

tatianasabrinapoggi@gmail.com

PROYECTO FIN DE CARRERA 


\section{la mujer digital}

Proyecto final de carrera de la titulación de Arquitectura dirigido por Miguel Mesa del Castillo y realizado durante los cursos 2014/2015 y 2015/2016, finalizado en Enero de 2016 obteniendo una nota de 10 y premio Matrícula de Honor.

La Mujer Digital es una investigación propositiva que explora la condición de habitabilidad y politicidad de una mujer en la ciudad contemporánea.

Este proyecto se apoya en trabajos y textos como El Pao de La Mujer Nómada extraído de Escritos de Toyo Ito, Un cuarto propio conectado de Remedios Zafra, Manifiesto Cyborg de Donna Haraway, Políticas de la naturaleza de Bruno Latour - La teoría de las Esferas de Peter Sloterdijk; textos que hablan de la mujer, del cuerpo, del ciborg, de cuartos propios y espacios conectados, de atmósferas, de esferas habitables, de territorios, de agentes sistémicos, de la domesticación del espacio, de identidades, de digitalización..; la información extraída, y el propio análisis de la realidad de cada día sirven para conformar una propuesta arquitectónica que intima con lo social, lo cultural y lo político del sujeto contemporáneo y su relación con la arquitectura y el territorio utilizando el mundo digital como herramienta.
Las arquitecturas que se proponen van desde la escala territorial -o global, en la que se propone un nuevo mapamundi-, pasando por la escala doméstica -tradicionalmente asociada a la arquitectura, en la que se propone un nuevo modelo de espacio o protocolo de actuación doméstica-, para acabar en la escala objetual -en la que se diseńan y construyen una serie de objetos tecnoafectivos que relacionan a La Mujer Digital con el resto de agentes humanos, tecnológicos y naturales a través de performances en vivo-.

El proyecto se divide en cuatro partes y un anexo; Mapas de la imaginación, La domesticidad en guerra, El cuerpo impropio y La digitalización toma el mando y un anexo que es un cronograma, a modo de diario.

El proyecto completo puede verse online en: https://archivoproyectosarquitectonicos.va.es/index.php/12-la-mujer-digitaltatiana-poggi 

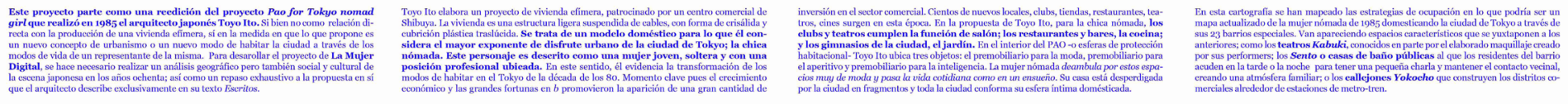

東京

prefectura de Tokyo -metrópolis- (都 -to ) IIIIIIIIIII $2.187,08 \mathrm{~km}^{2}$ =área metropolitana de Tokyo
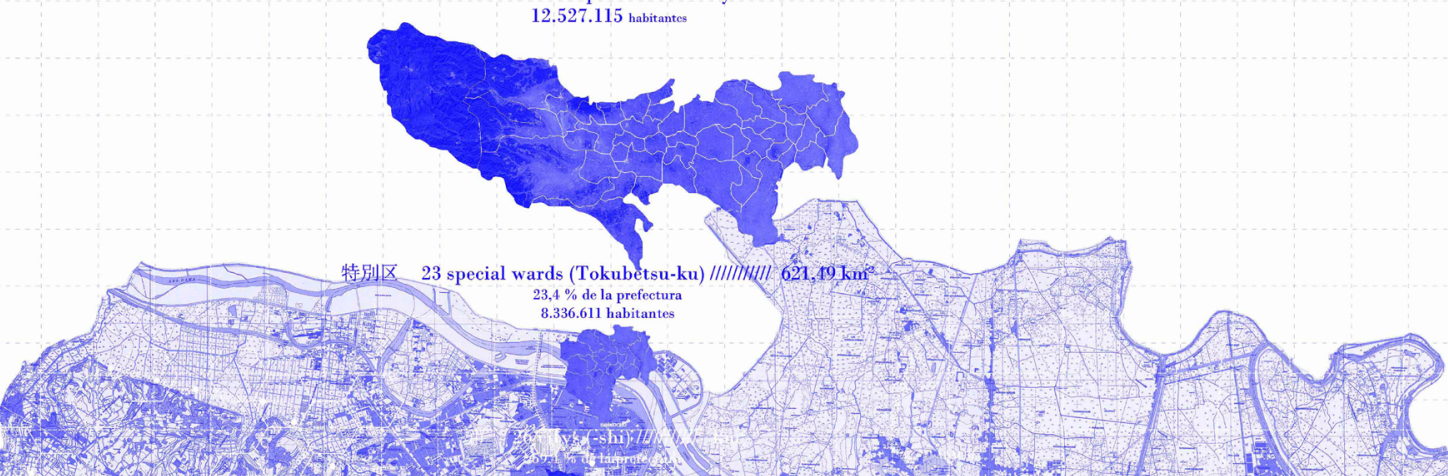

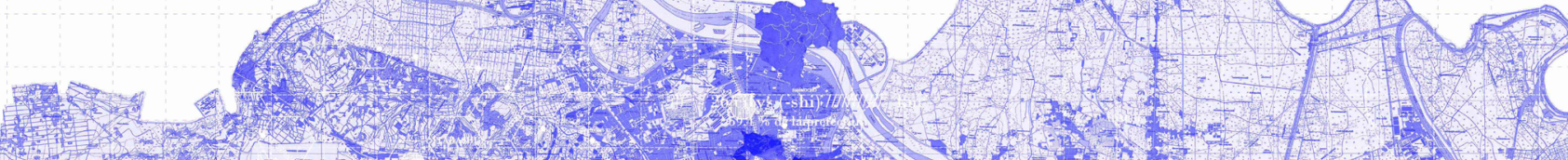

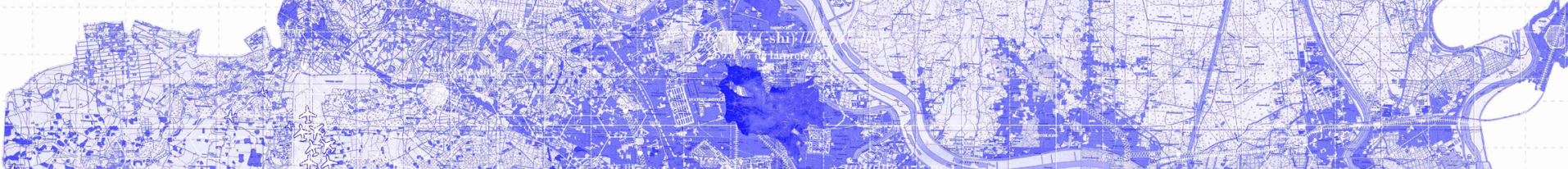

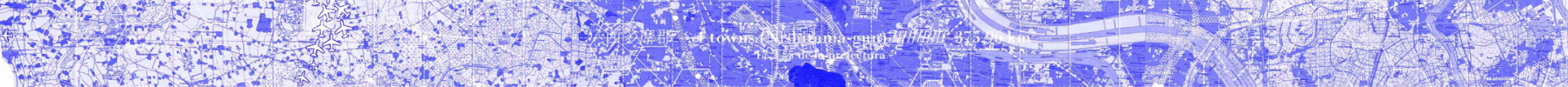

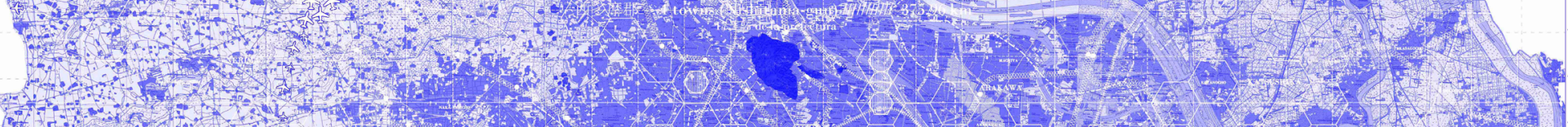

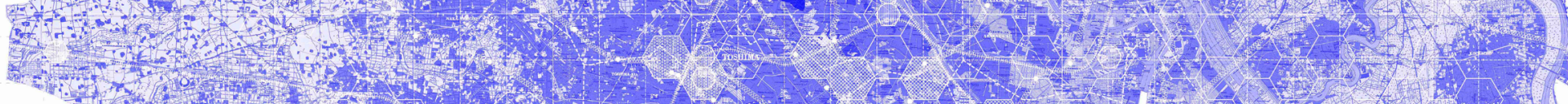

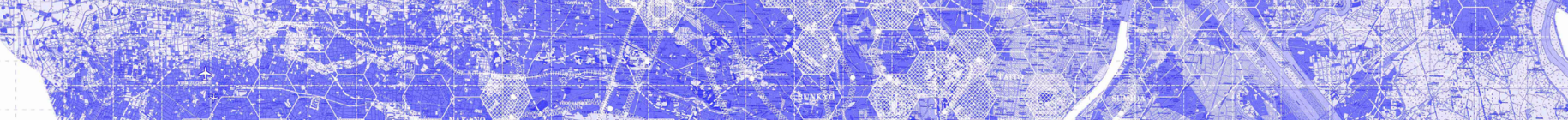

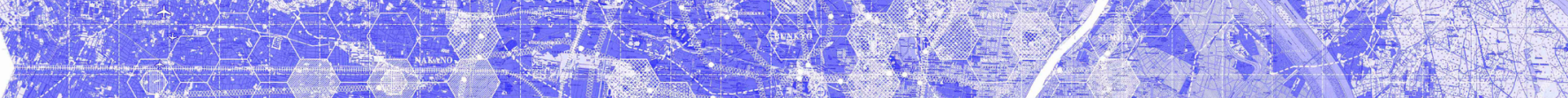

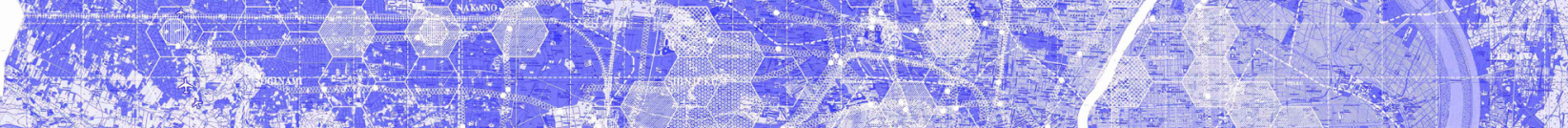

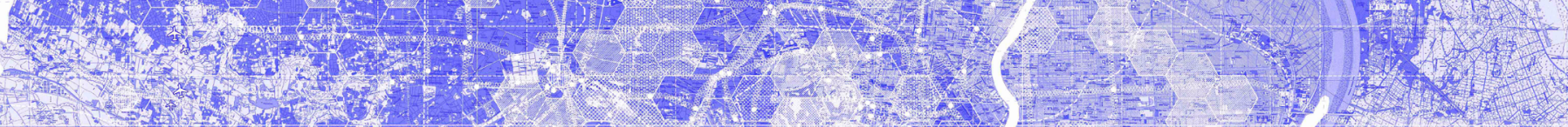

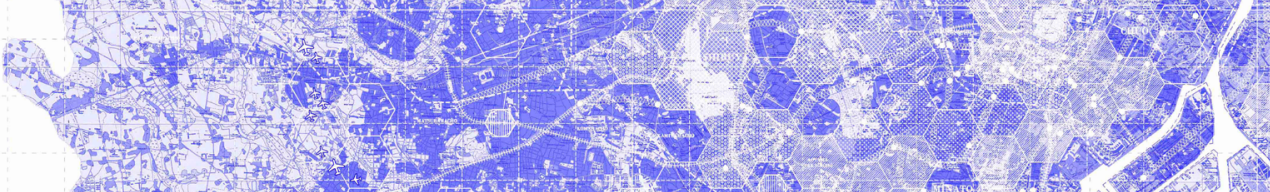

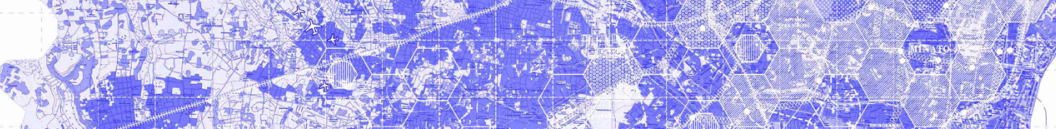

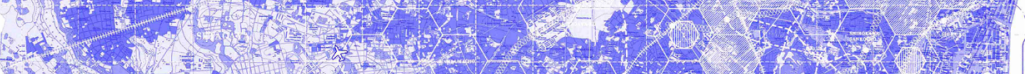

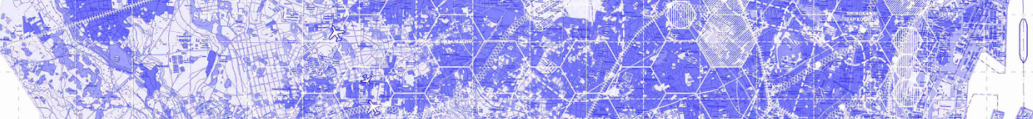

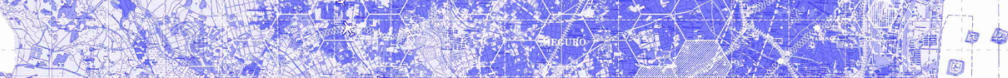

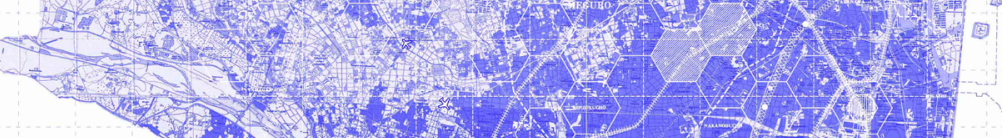

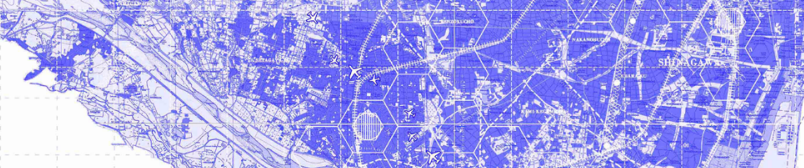

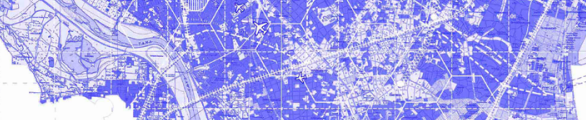
$4=\left(1+2 x^{2}=\right.$ (1) $(1)+2=$

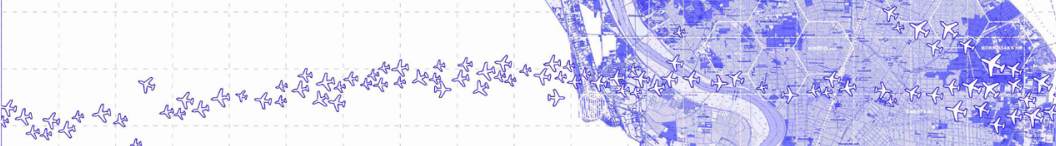

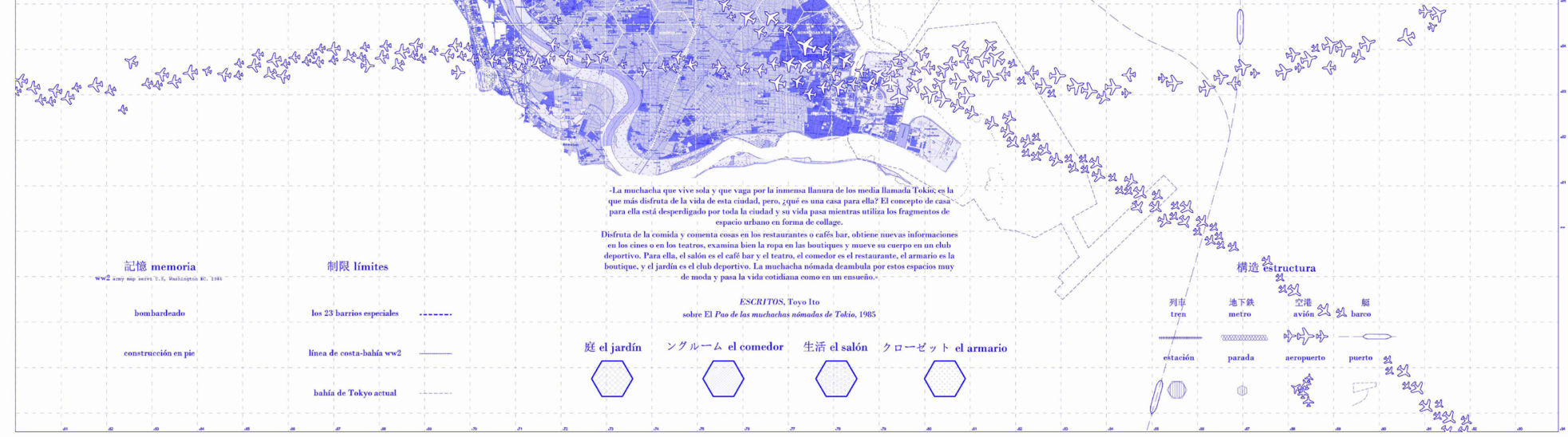




\section{La Mujer Digital es una}

investigación propositiva que explora la condición de domesticidad y politicidad de una mujer en la ciudad contemporánea. En 1985 el arquitecto japonés Toyo Ito elabora un proyecto de vivienda efímera, patrocinado por un centro comercial de Shibuya. Un modelo doméstico para lo que él considera el mayor exponente de disfrute urbano de la ciudad de Tokyo; la mujer nómada. Este personaje es descrito como una mujer joven, soltera y con una posición profesional ubicada. ¿Quién es esta mujer después de treinta años? La mujer nómada contemporánea ha dejado de ser nómada. Ya no deambula por la ciudad aprovechándose de las características que le ofrece cada lugar, porque está en todos los lugares a la vez. Es un ser digital. La mujer digital. La disgregación de la ciudad, la globalización y el grado de tecnologización que ha alcanzado nuestro habitar, entre otros, es el potenciador de una vida dispersa, físicamente, pero concentrada a la vez, virtualmente. ¿Porqué comer en los restaurantes de tu ciudad si puedes hacerlo en Roma o Barcelona? El salón que se convertía en los clubs y teatros de la ciudad, pasa a ser Ibiza o Bangkok, el jardín es Marrakech y las Islas Maldivas; la mujer digital duerme en hoteles que la hospedan y domestica apartamentos bandb; su entorno profesional y académico se sitúa en torno a Londres y Nueva York. No necesita un premobiliario para la moda, el aperitivo o la inteligencia porque tiene un smartphone, una tablet y un ordenador portátil. Todo lo que necesita lo transporta consigo, en su traje y en su maleta. 


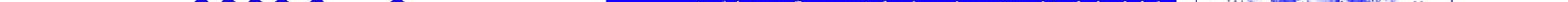




\section{Autogeografía es el nuevo atlas}

mundial. Un mapamundi unipersonal. Válido para un único agente. La mujer digital. Un nuevo planisferio terrestre con una proyección geográfica de la esfera; editada, mutada, transformada. Dicha mutación no se define por cortezas terrestres. Los tradicionales bordes territoriales dejan de tener sentido. Dejan de ser geográficos, topográficos o geológicos y pasan a convertirse en bordes configurados por: autovías de circunvalación que conectan aeropuertos con centros urbanos, líneas de tren de alta velocidad, líneas de alta tensión, líneas de telefonía e internet, ondas wifi, redes $3 \mathrm{G} . .$. Estas nuevas ciudades - estado se convierten así en ciudades - producto, en musts urbanos, compuestos por: aeropuertos, puestos de comida con ruedas, centros de adelgazamiento, apartamentos b\&b, centros comerciales, mercadillos, ateliers de artistas, centros de cosmética bio, hoteles, facultades universitarias, cafeterías con gatos, galerías de arte, tiendasbiblioteca, mercados vintage, clubs, tiendas de museos, museos, photocalls, selfie-fondos urbanos. En el número 9 de la revista Archigram de 1970, aparece una fotografía de un hombre sentado en el campo, pescando y viendo una película en su televisión portátil. Ya en esa época se estaba proponiendo una nueva concepción del urbanismo. El urbanismo había dejado de ser la ciudad para convertirse en las acciones cotidianas que en ella se producían. Ahora esos acontecimientos analógicos también son digitales. 


\section{atoogsonagia}
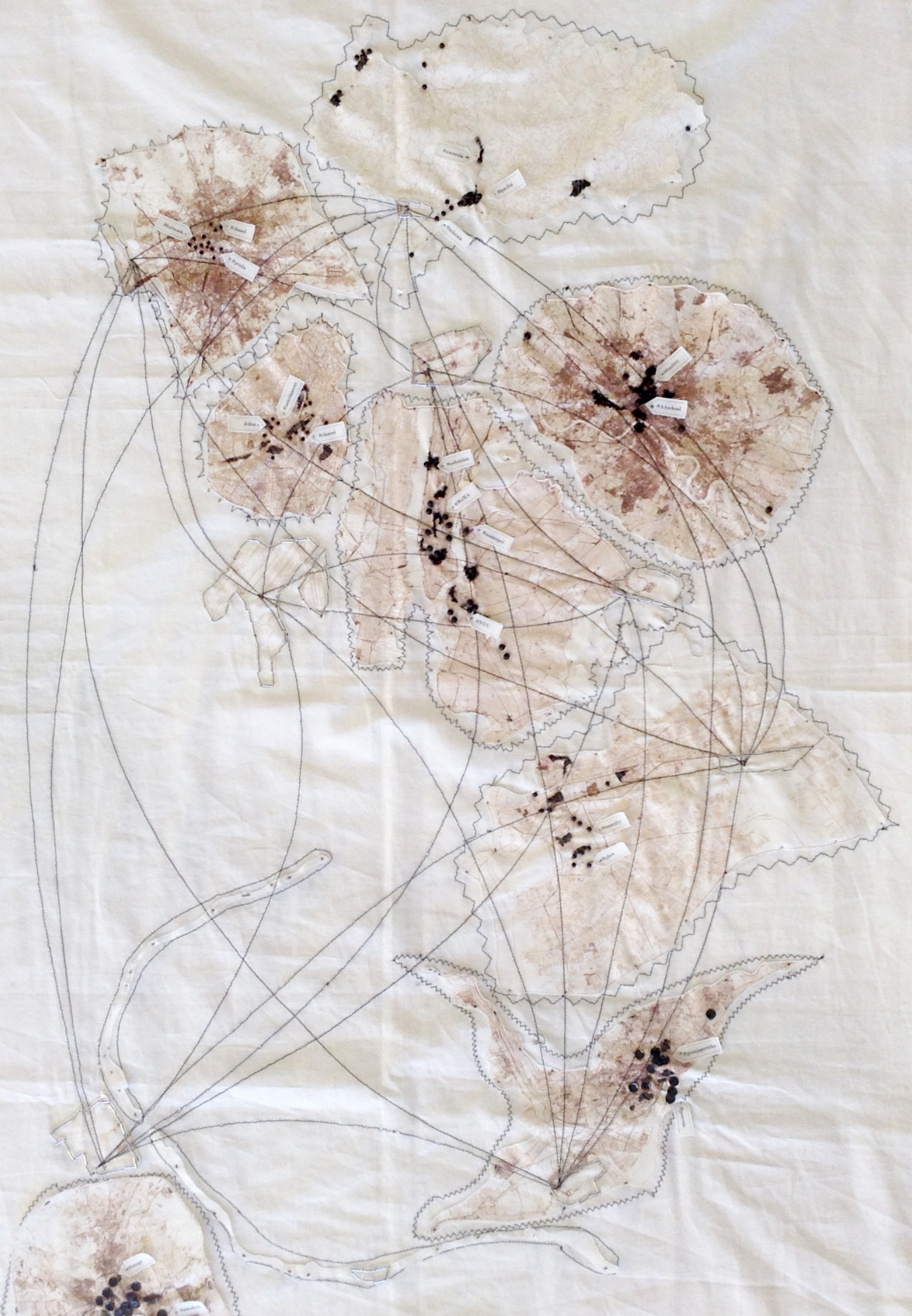


\section{Contrageografía es el mapa}

mundial oculto. Un catálogo de territorios que le son inherentes a la autogeografía. El fondo trasero. El

cuarto oscuro. Se trata de una cartografía que pretende dar visibilidad a los territorios de contrapoder con los que la mujer digital no se relaciona físicamente, pero de los que sí se aprovecha. ¿Dónde se fabrica la tecnología que consume? ¿y la ropa? ¿las sustancias químicas? En Contrageografía se mapean territorios como Tamil Nadu, Tanger, Arteixo y Americana como centros neurálgicos de producción textil -que la mujer digital consumirá en París o Milán-, otros como Los Montes Cardamomos, el VRAEM o Tonala que son productores de sustancias químicas -que la mujer digital consumirá en Bangkok o Ibizao Bangalore, Vinh Phuc o Schenzen, principales territorios productores de tecnología exportada a los países del primer mundo, en los que consume La Mujer Digital, así como islas artificialmente ampliadas, como la isla Bolifushi, en las Maldivas. A través de una nueva geografía multiescalar a modo de negativo de la autogeografía, se ha trazado una conjunción de territorios preexistentes para dar visibilidad a los hechos que son consecuencia de la vida del sujeto contemporáneo occidental tales como evidenciar las 68 horas semanales de una mujer adolescente en Bangladesh que cobra 1,3 euros al día y no puede objetar no tener derechos laborales; o los trabajadores que fabrican dispositivos iphone para foxconn en la ciudad de Schenzen -la ciudad con más productoras de tecnología móvil del mundo- de los que se han ocultado multitud de suicidios; o la tala masiva de árboles en las selvas de Camboya, para producir el éxtasis que se vende en Ibiza. 


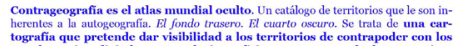

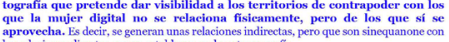

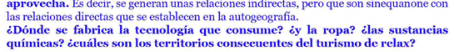

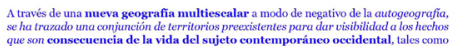

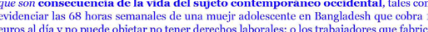

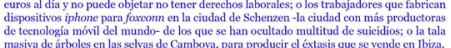

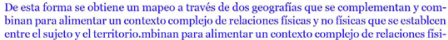

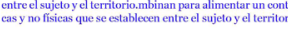

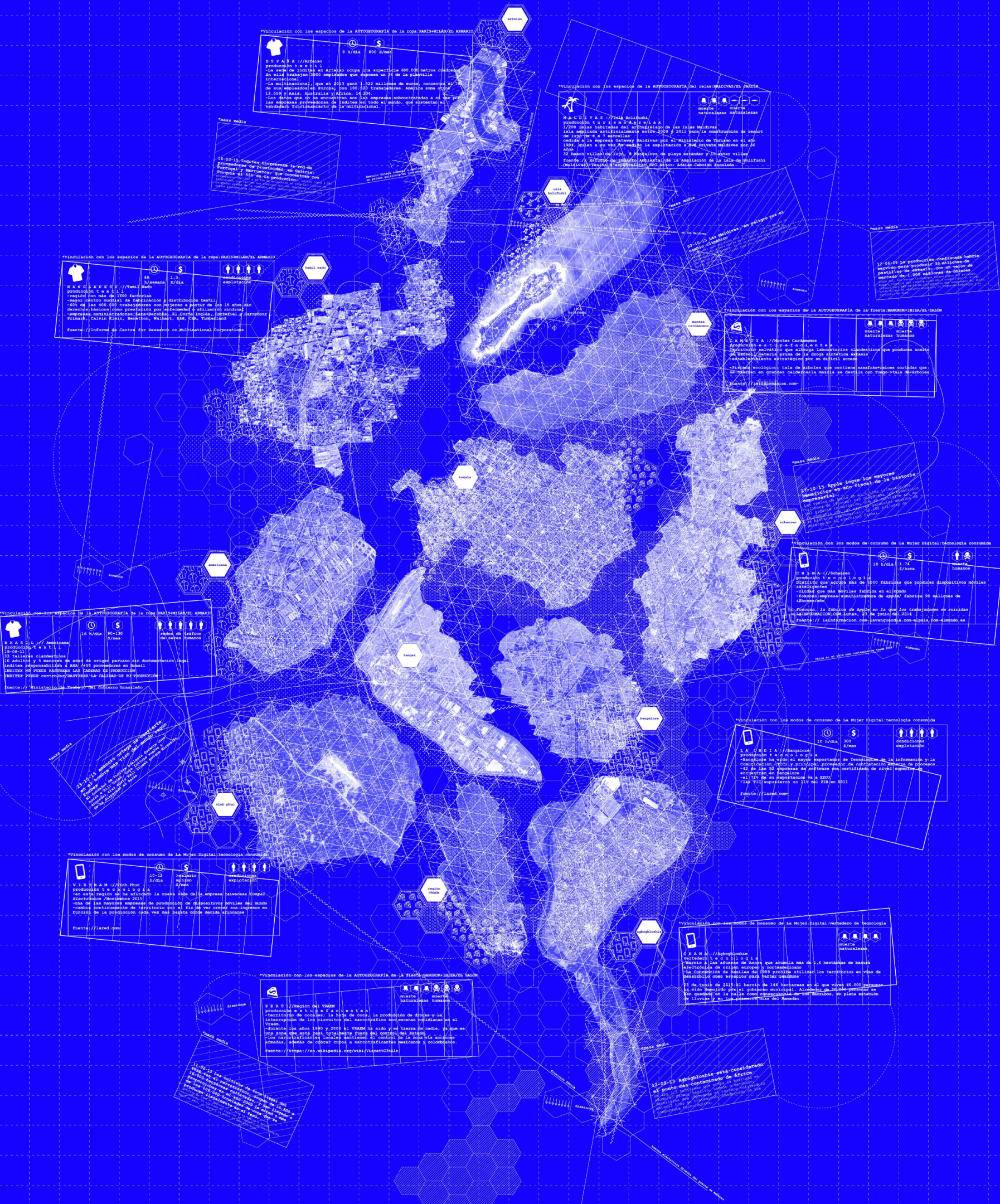

$+$

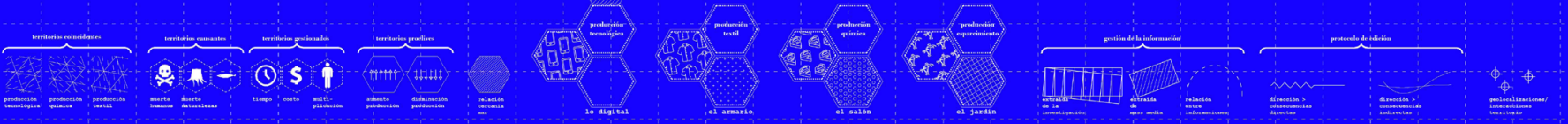




\section{domesticidad compartida es}

un nuevo modelo doméstico resultado de la transformación de las formas de habitar contemporáneas y de una crisis de la pertenencia. Una forma de vida concentrada digitalmente pero dispersa físicamente. De alguna forma, el estallido económicosocialpolítico y la consecuente presión social ha conducido a la población joven a infravalorar la idea de la posesión de un espacio propio y al aumento de los viajes por necesidad. Dentro de esta transformación continua del sentimiento de pertenencia a un lugar en esta sociedad del capitalismo avanzado, esta investigación propone que el individuo está cada vez más identificado con los objetos que posee, que lleva consigo; su ropa y sus más preciadas pertenencias, porque con ellas, es capaz de sentirse él mismo en un espacio que no le es propio. Los lugares de la autogeografía que habita La Mujer Digital son espacios domésticos que no le son propios: hoteles, apartamentos airbandb, openhouses, etc. Estos lugares le brindan las funciones básicas que ofrece un espacio arquitectónico: confort térmico, espacios de higiene, lugar para descansar y almacenar sus pertenencias microtemporalmente. A través de los objetos afectivos que existen en esos espacios, La Mujer Digital adquiere un primer grado de pertenencia. Estos objetos le hacen sentir pertenenciente al lugar, a la casa, al barrio, a la ciudad. Se identifica con ellos porque le son recurrentes a los suyos propios. Es por ello, que podemos decir que esta nueva forma de habitar ciudades a través de plataformas web de viviendas compartidas, conlleva que todos tenemos una casa en cada ciudad del mundo. Una práctica que necesita del soporte digital para existir, pero es inherente a la vivencia física del espacio arquitectónico. En este dibujo, se propone una nueva ficción doméstica, un espacio arquitectónico resultado de la unión de viviendas reales extraídas de plataformas web, que corresponden a las ciudades de la autogeografía de La Mujer Digital. Lo que construye estos espacios son los objetos tecnoafectivos de los dueños que allí viven, son estos los que facilitan los sentimientos de pertenencia cuando La Mujer Digital los ocupa. Ella es la protagonista de la cartografía. 


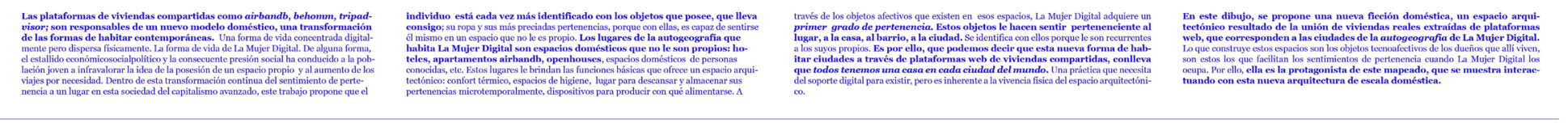

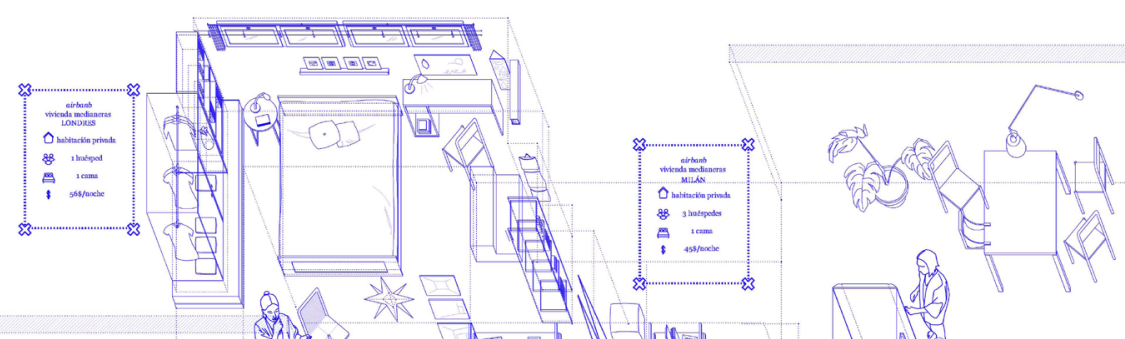

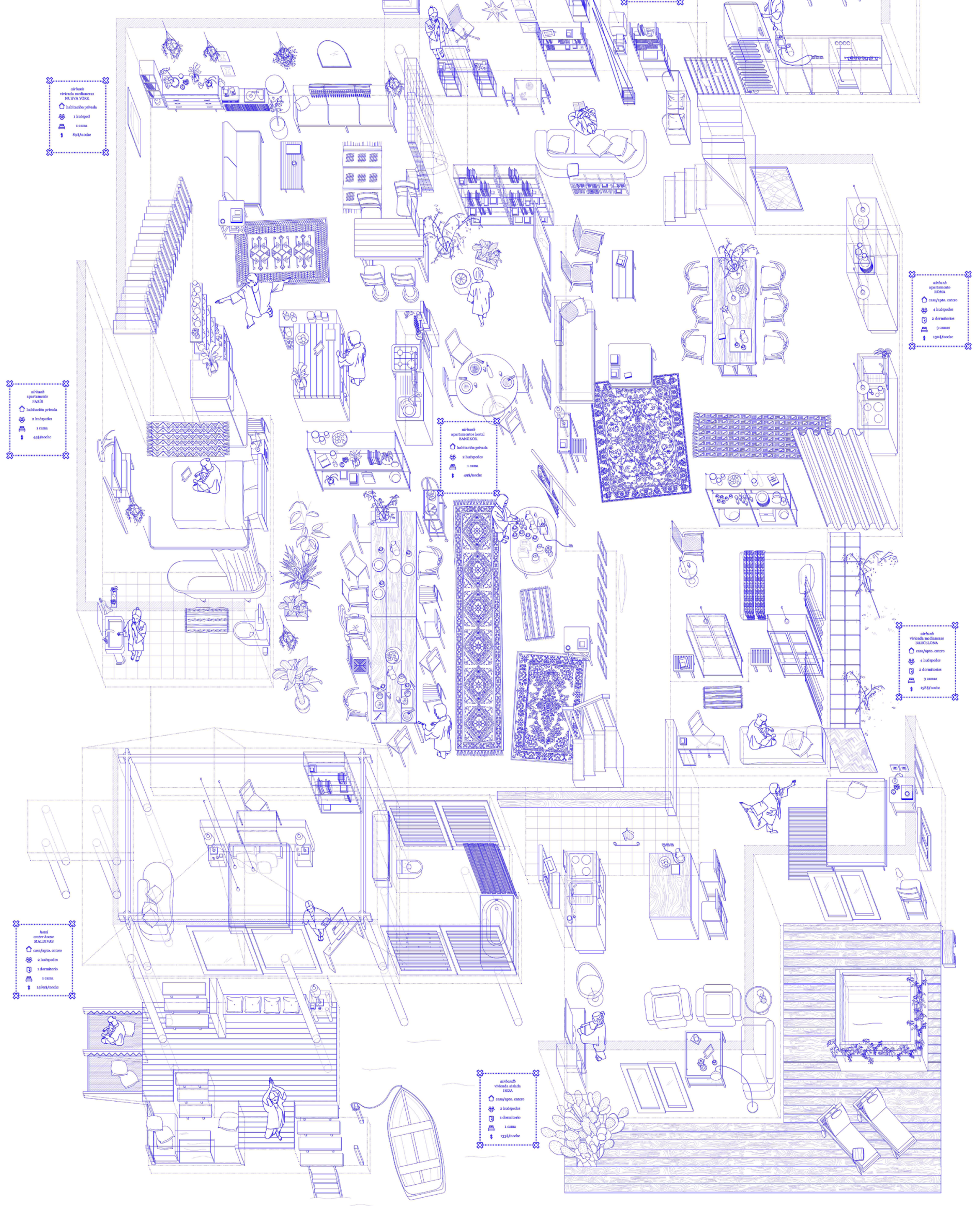




\section{dispositivos tecnoafectivos}

para la adquisición de pertenencia a un lugar. En la filosofía de Foucalt, un dispositivo es un conjunto de estrategias que condicionan ciertos tipos de saber y que a a la vez, son condicionados por él. Es un cruce de relaciones de poder y relaciones de saber. Según los diccionarios franceses de la época, un dispositivo tenía un significado jurídico, un significado tecnológico y un significado militar. Pero es el análisis y propuesta que extrae Giorgio Agamben de la teoría de Foucalt sobre dispositivos, la que me interesa. Agamben propone una partición general de lo que existe en dos clases: los seres vivientes (a los que yo llamo humanos) y los dispositivos (en los que englobaría tecnologías y naturalezas) acercándonos de esta forma a las propuestas de otro filósofo como es Bruno Latour. Como Agamben propone llamaré dispositivo literalmente a cualquier cosa que de algún modo tenga la capacidad de capturar, orientar, determinar, interceptar, modelar, controlar y asegurar los gestos, conductas, las opiniones y los discursos de los seres vivientes. Así, propongo que el dispositivo sea aquella cosa natural o tecnificada que es capaz de interceder entre el humano y el medio, creando nuevas relaciones de poder y saber entre el humano y su entorno. El dispositivo es una arquitectura posibilitadora. ¿Y qué posibilita como objeto arquitectónico el dispositivo? La adquisición de un primer grado de pertenencia a un espacio, a un lugar, a una casa que no nos es propia. La Mujer Digital habita temporalmente estas domesticidades compartidas, repletas de dispositivos afectivos. En estos lugares La Mujer Digital es una invitada, una ocupa, una refugiada. ¿Cómo dejar de serlo? Cuando llegamos a un apartamento airbandb o similar, comenzamos a depositar nuestras pertenencias en el mismo, a realizar actividades cotidianas como cocinar, maquillarnos, ducharnos o limpiar. Es a través de la realización de estas actividades y la relación que comenzamos a mantener con estos objetos tecnoafectivos que alli se encuentran -que además comienzan también a entremezclarse con los nuestros propios- como La Mujer Digital inicia un proceso de apropiación del espacio, tan significante en el sentido de la construcción de la arquitectura. Adquiriendo un primer grado de pertenencia al mismo estamos consiguiendo ser parte de un espacio arquitectónico, sin serlo legalmente, oficialmente, ni de ninguna otra tradicional forma entendida hasta hoy. Es por ello, que estos objetos son, irremediablemente, objetos arquitectónicos. 


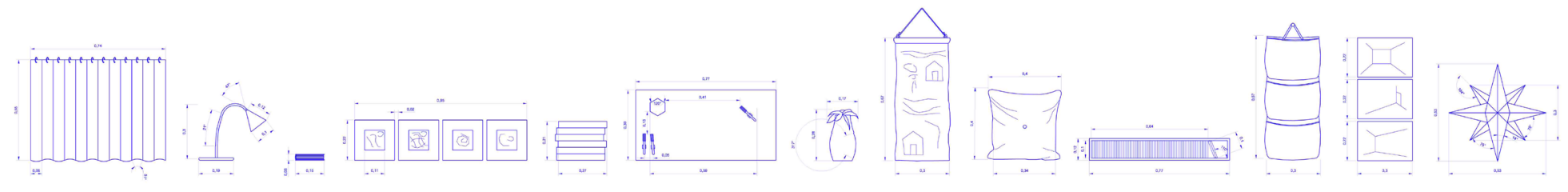

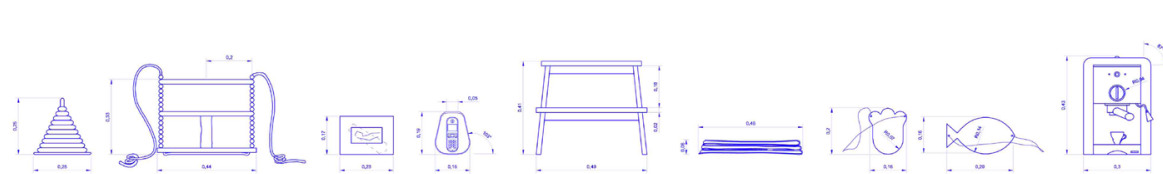
90.

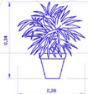

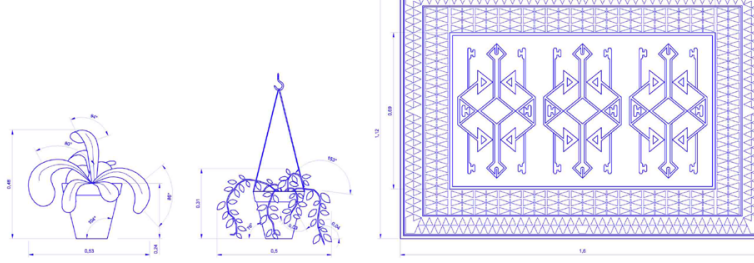

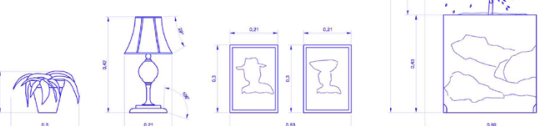
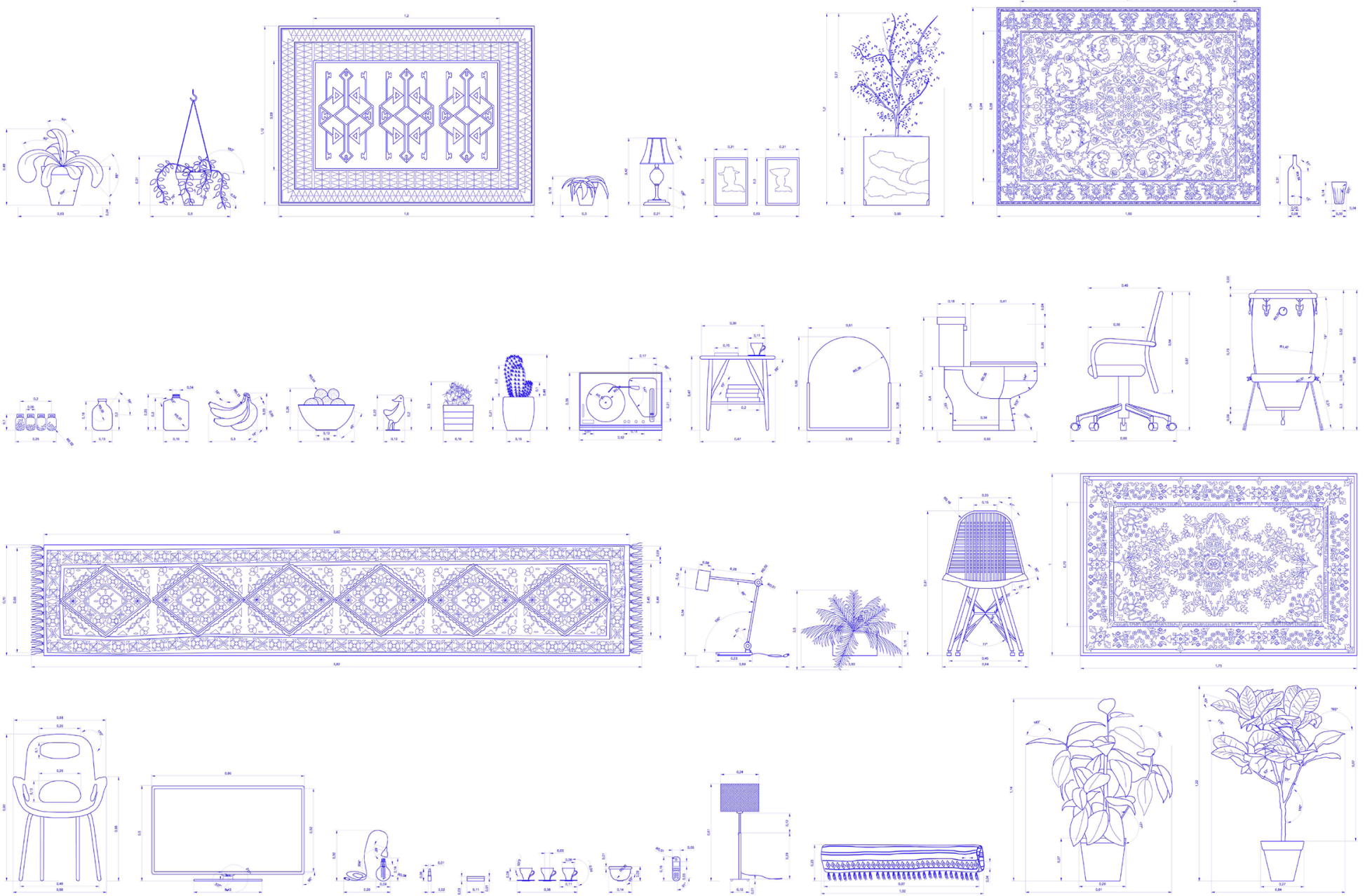

$\therefore$
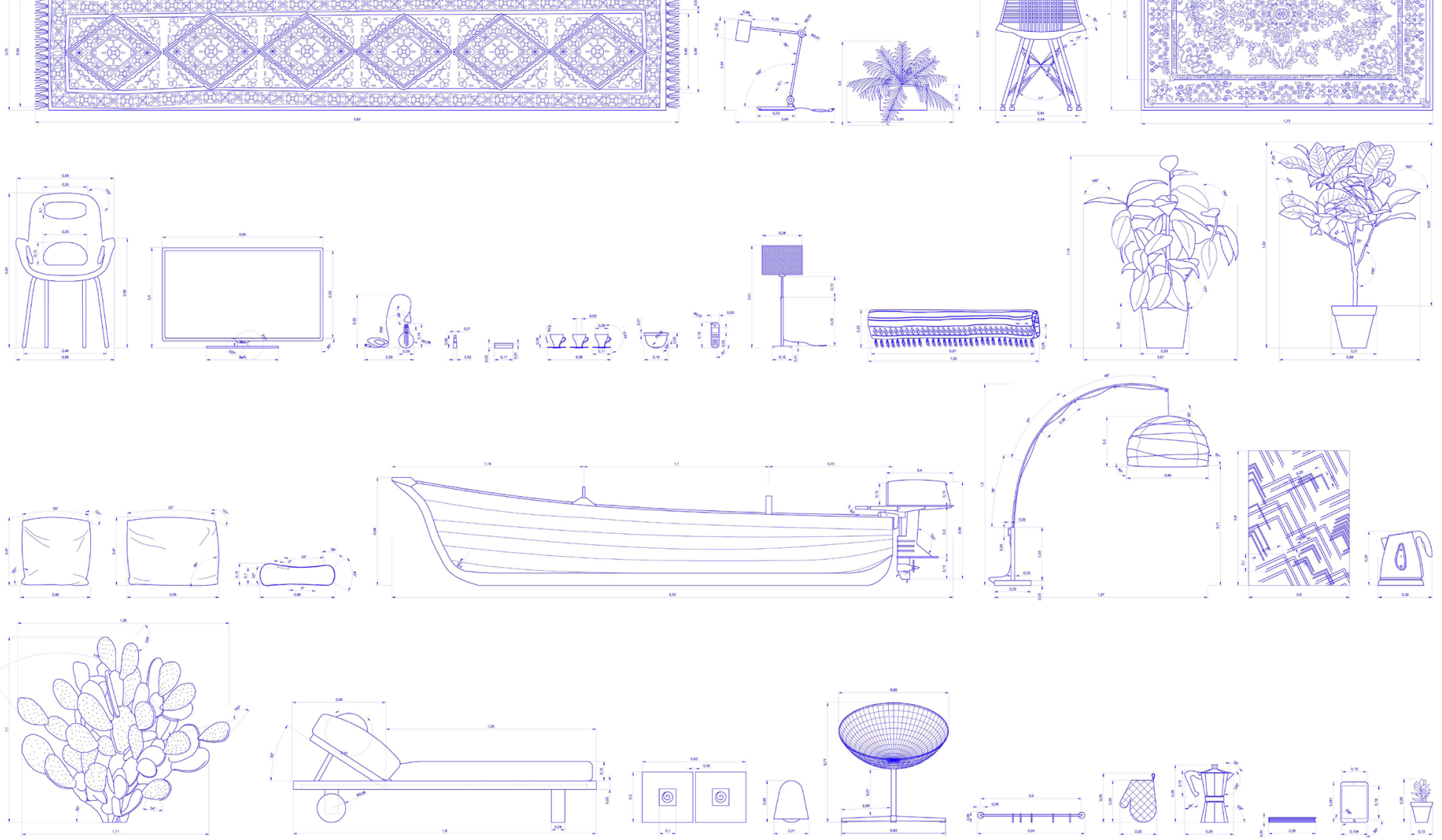

(Q)
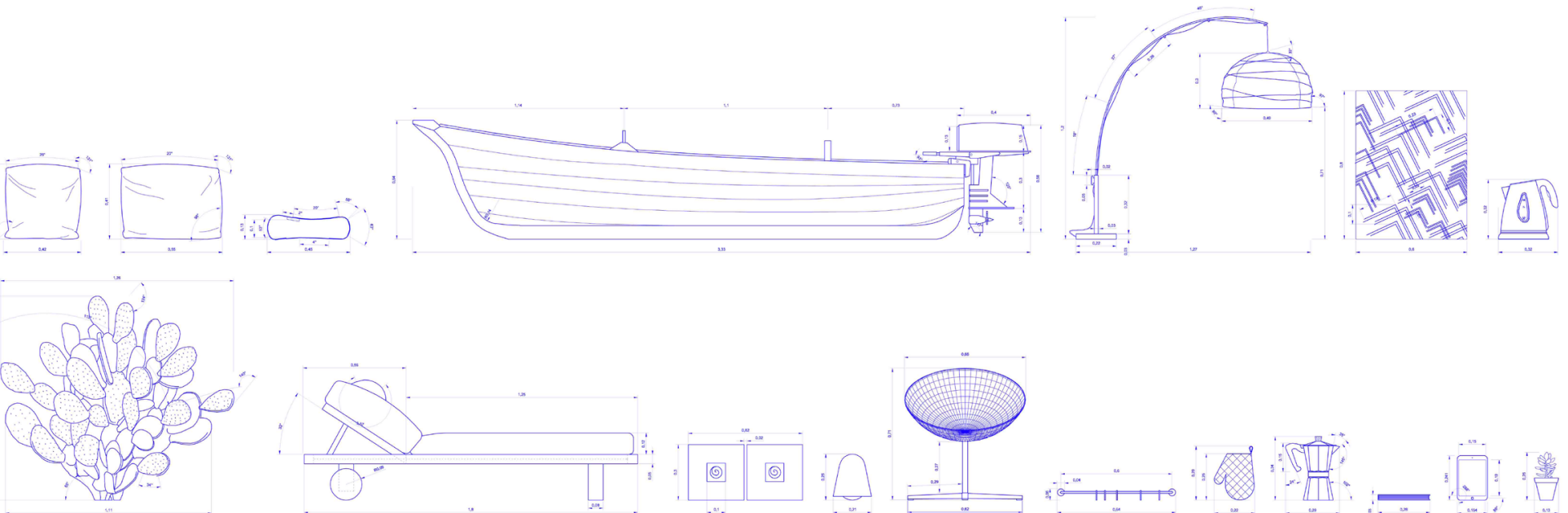

睢 : 


\section{ceremonias de anfitrionazgo}

para la adquisición de pertenencia a un lugar. En el proceso de domesticación de los espacios no propios que ocupa La Mujer Digital, hemos visto que un primer grado de pertenencia se obtiene a través de la interacción con los dispositivos tecno-afectivos que existen en esos espacios y con los propios objetos que La Mujer Digital lleva en su maleta. Al llegar al nuevo espacio a ocupar, se generan nuevas relaciones al realizar actividades cotidianas como ducharse, maquillarse, leer, descansar, o practicar yoga. No obstante es cuando invita a otras personas a este espacio, convirtiéndose en un maestra de ceremonias, cuando el espacio realmente le pertenece. Este segundo grado de pertenencia, o capacidad para sentirse "como en casa" de forma completa, es adquirido a través de una ceremonia o acontecimiento que ella lleva a cabo en los lugares que la hospedan. Estas ceremonias estarán directamente relacionadas con actividades cotidianas que se suelen realizar socialmente en grupo en un espacio propio. Se propone que a través de la ceremonia de la fiesta, la ceremonia de la cena y la ceremonia del relax, se consiga generar un sentimiento pleno de pertenencia en cualquier ciudad del mundo. Para ello, se diseñan una serie de protocolos, además de una vestimenta y escenografía, que configuran la complejidad del acontecimiento dando lugar a una arquitectura festiva. 
La Mujer digital es la propuesta arquitectónica resultado del análisis de la transformación de las formas de habitar
contemporáneas La crisiseconomica yla consecuente presion social ha conducido la población joven ainfravalorar la dea de la posesión de un espacio proopio y al aumento de la necesidad de viajar. Dentro de esta transformación continua del sentimiento de pertenencia a un lugar en esta sociedad, creemos que el individuo está cada vez más identificado con los objetos que posee, que lleva consigo; su ropa y sus más preciadas pertenencias, porque con ellas, es capaz de sentirse el mismo en un

través de ra

portamos encima y vamos sacando de nuestras maletas y generando relaciones a través de actividades cotidianas en la
casa/barrio/ciudad, pero es sin duda cuando invitas a otras personas a este espacio, convirtiéndote en un mestro de Este segundo grado de pertenencia, es adquirido a través de diseño/celebración de ceremonias. Estas ceremonias estarán directamente relacionadas con actividades cotidianas que se suelen realizar socialmente en grupo en thn espacio propio. Se propone que a través de .
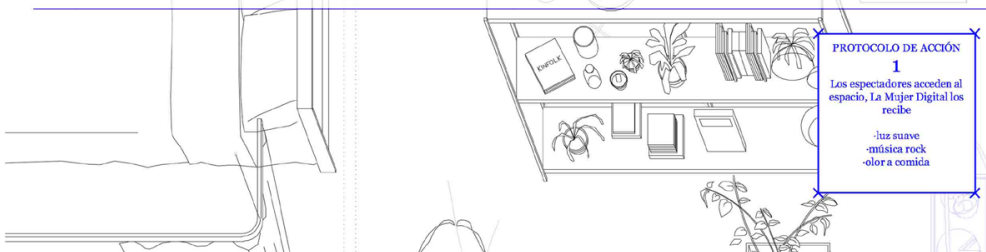

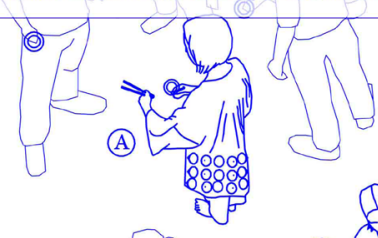

$\square$
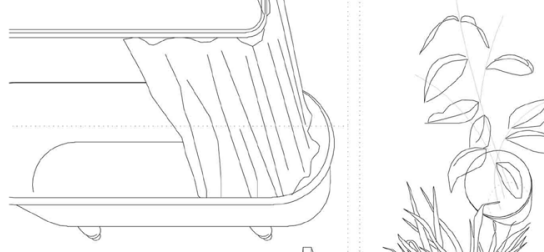

PQD
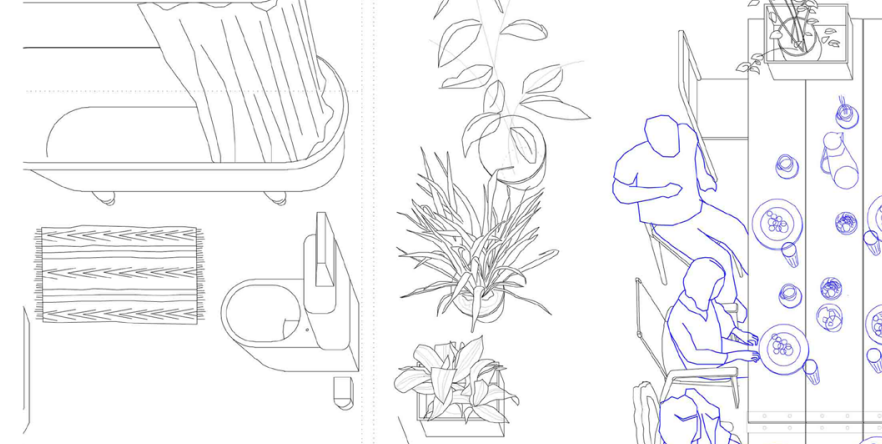

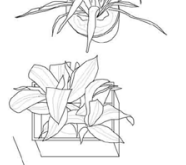

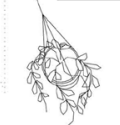

atroc

(2)

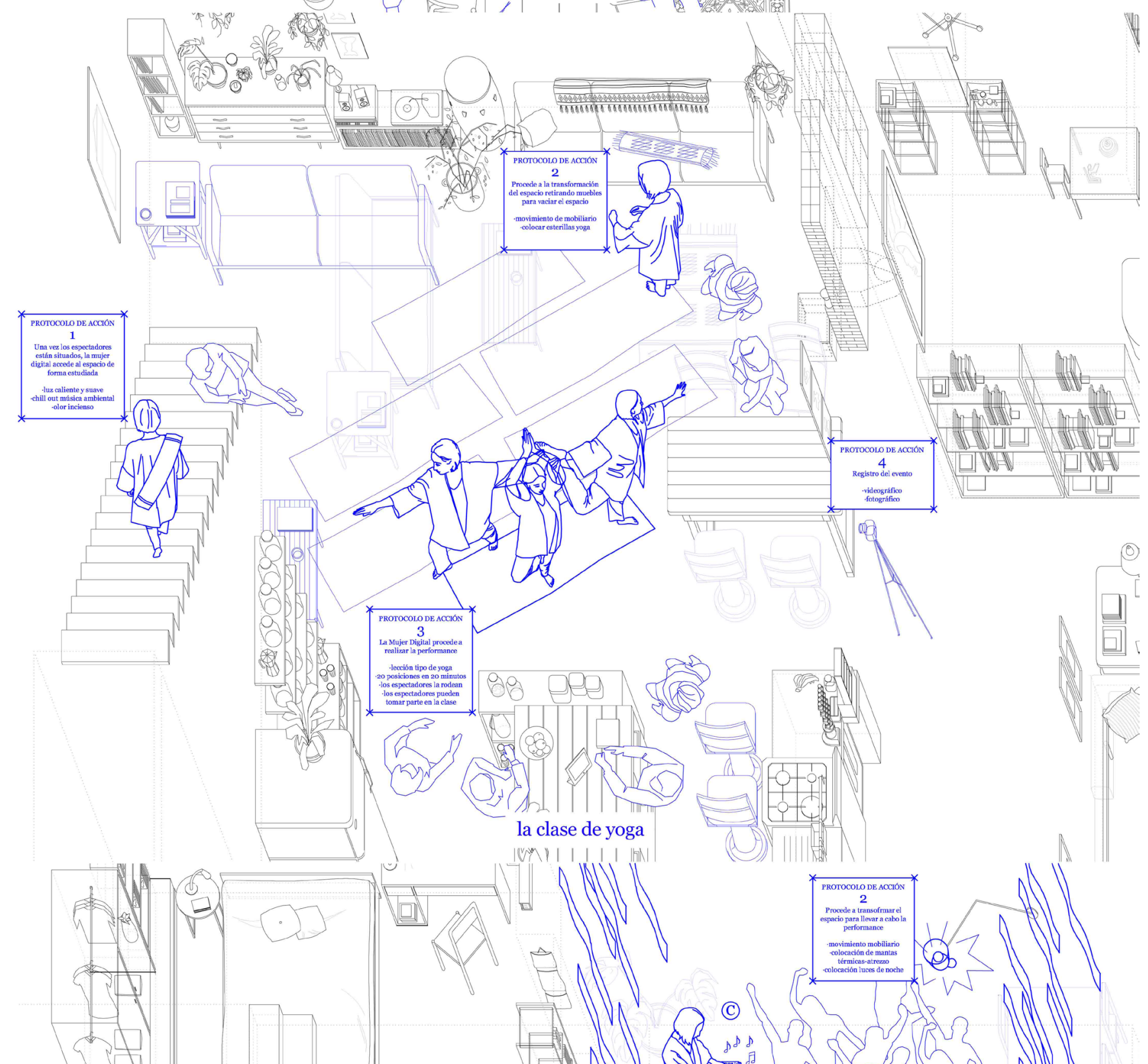

काषे

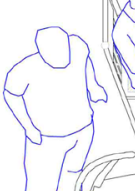

(1)

证

(B)

.

12

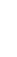




\section{arquitectura performativa}

Con la intención de continuar esta propuesta con un acercamiento a la realidad arquitectónica, y a la autoproducción o construcción de la propuesta del proyecto por mi misma, en este momento, decido realizar una performance que emule las ceremonias que se proponían para la domesticación de espacios. De esta forma, se diseña un acontecimiento, La Ceremonia, El traje y una sere de dispositivos necesarios que La Mujer Digital necesitará para llevar a cabo esta experiencia vivencial. El traje, compuesto por tres tejidos o capas superpuestas, se diseña y confecciona a mano, añadiendo sobre él los objetos propuestos para la realización de La ceremonia. Estas capas van desde la más cercana a la piel, el traje dermatológico, hasta una capa a modo de manto, pasado por la capa central, dotada de los utensilios. El Manto-Mantel-Manta es un elemento que relaciona naturalezas, tecnologías y humanos, con La Mujer Digital. Se plantea como un jardín digital, el jardín de microchips que planteaba Toyo Ito, un potenciador del espacio urbano. La Mujer Digital es un nuevo flujo en la ciudad, y el manto que porta se ha diseñado como una extensión de la propuesta de Toyo Ito, siendo las relaciones comunes entre lo urbano y el microchip: la fluidez, la multiplicidad de capas y la fenomenalidad, características también de la prenda. La Ceremonia, consta de cuatro partes diferenciadas y pretende dar voz a todos aquellos representados. Se diseña en toda su amplitud, llevandola a la práctica como performance, realizada en un evento público el 23 de Enero de 2015.

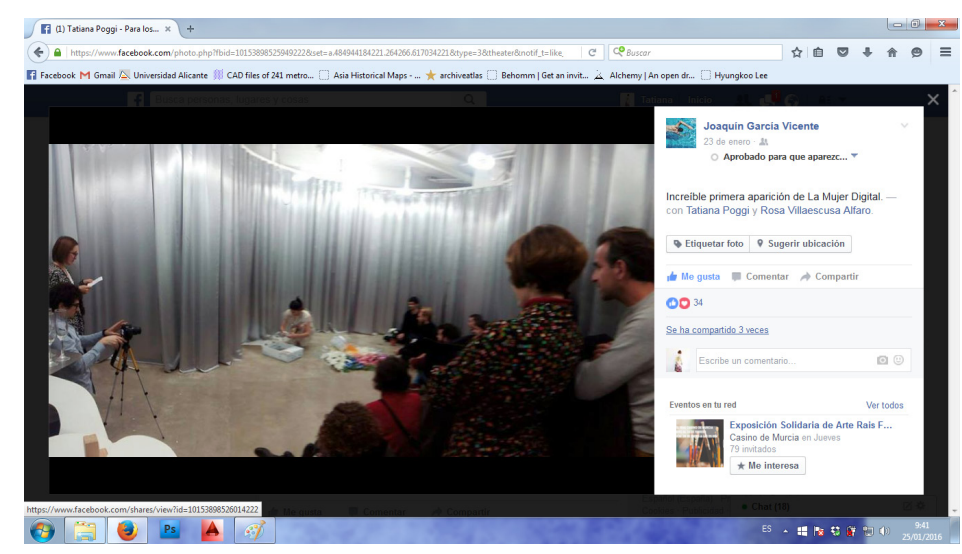


El Manto-Mantel-Manta es un elemento que relaciona naturalezas, tecnologías y humanos, con La Mujer Digital. Se plantea como un jardín digital, el jardín de microchips que planteaba Toyo Ito, un potenciador del espacio urbano. La Mujer Digital es un nuevo flujo en la ciudad, y el manto que porta se ha diseńado como una extensión de la propuesta de Toyo Ito, siendo las relaciones comunes entre lo urbano y el microchip: la fluidez, la multiplicidad de capas y la fenomenalidad, características también de la prenda.

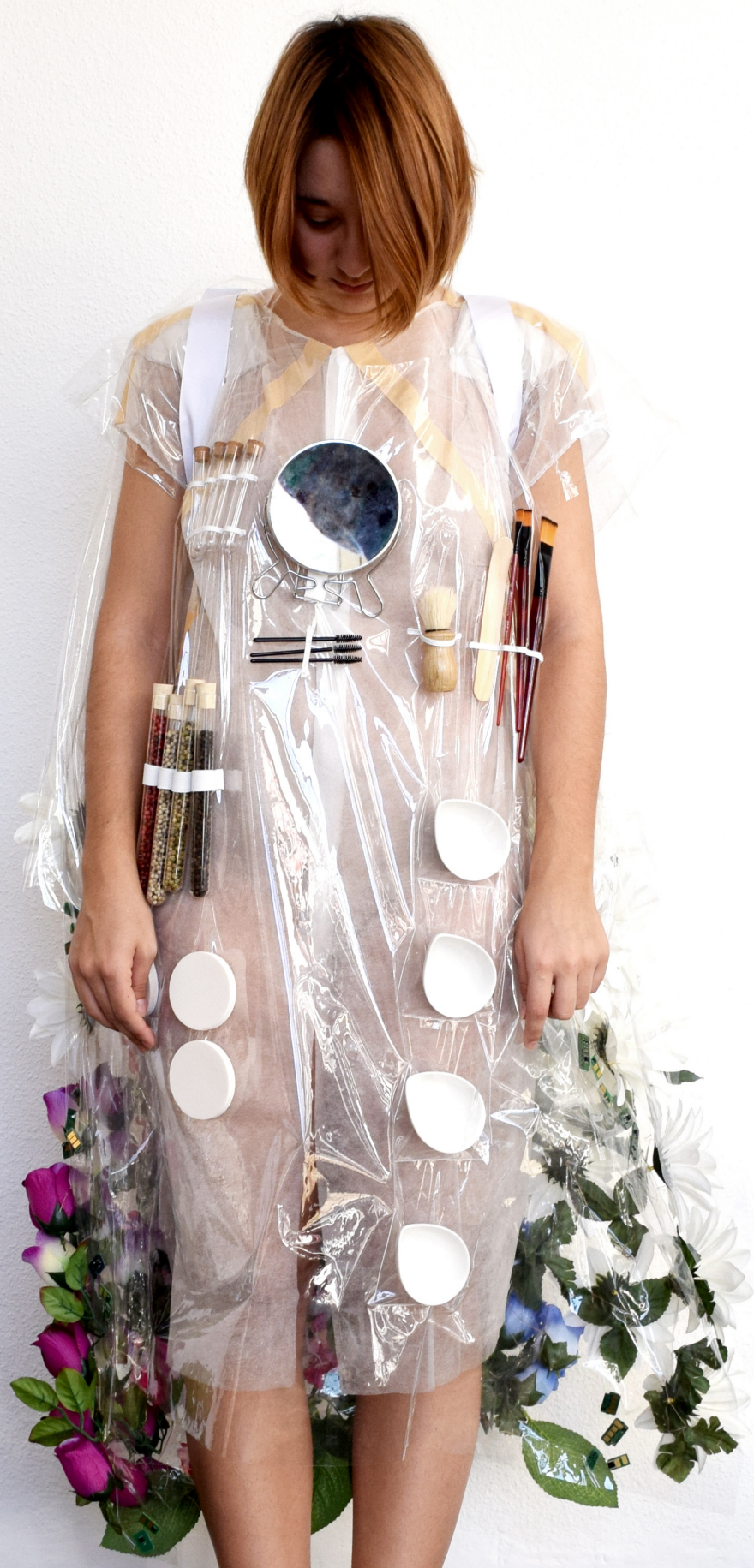




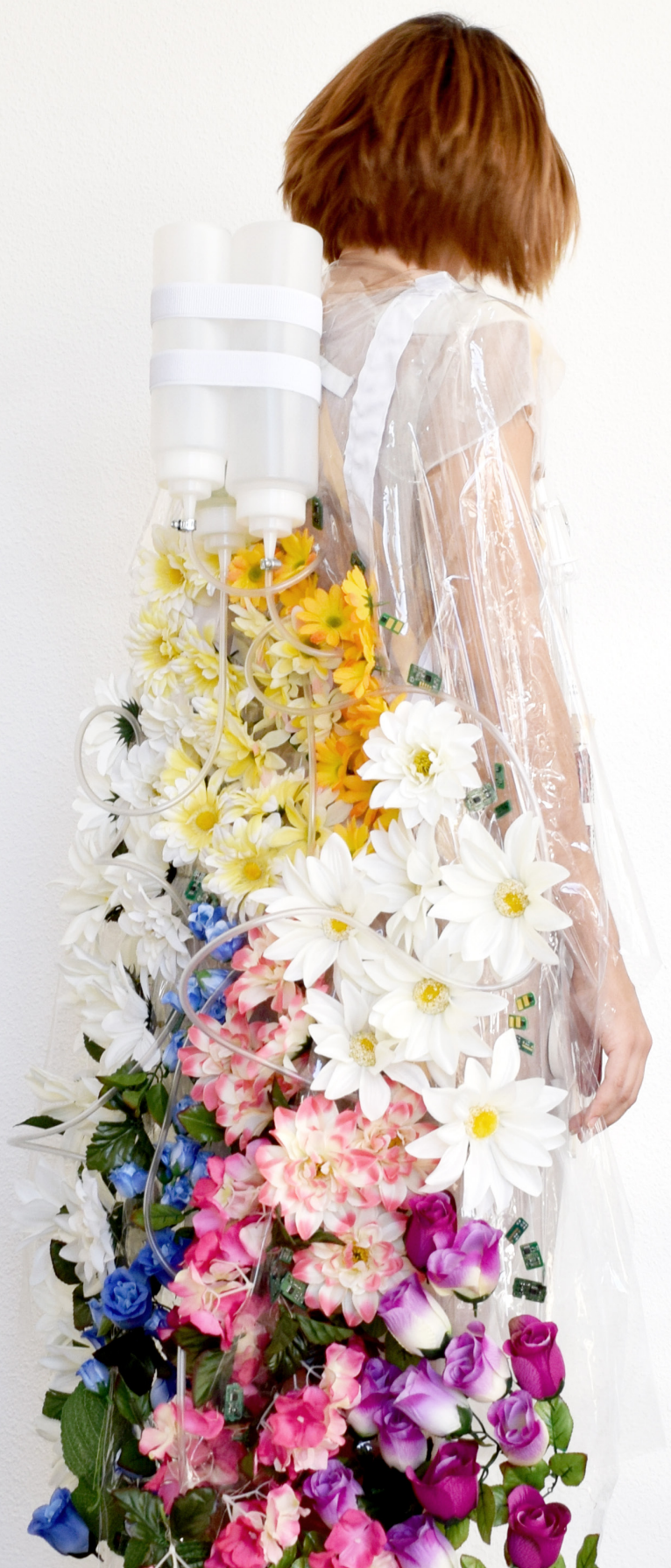




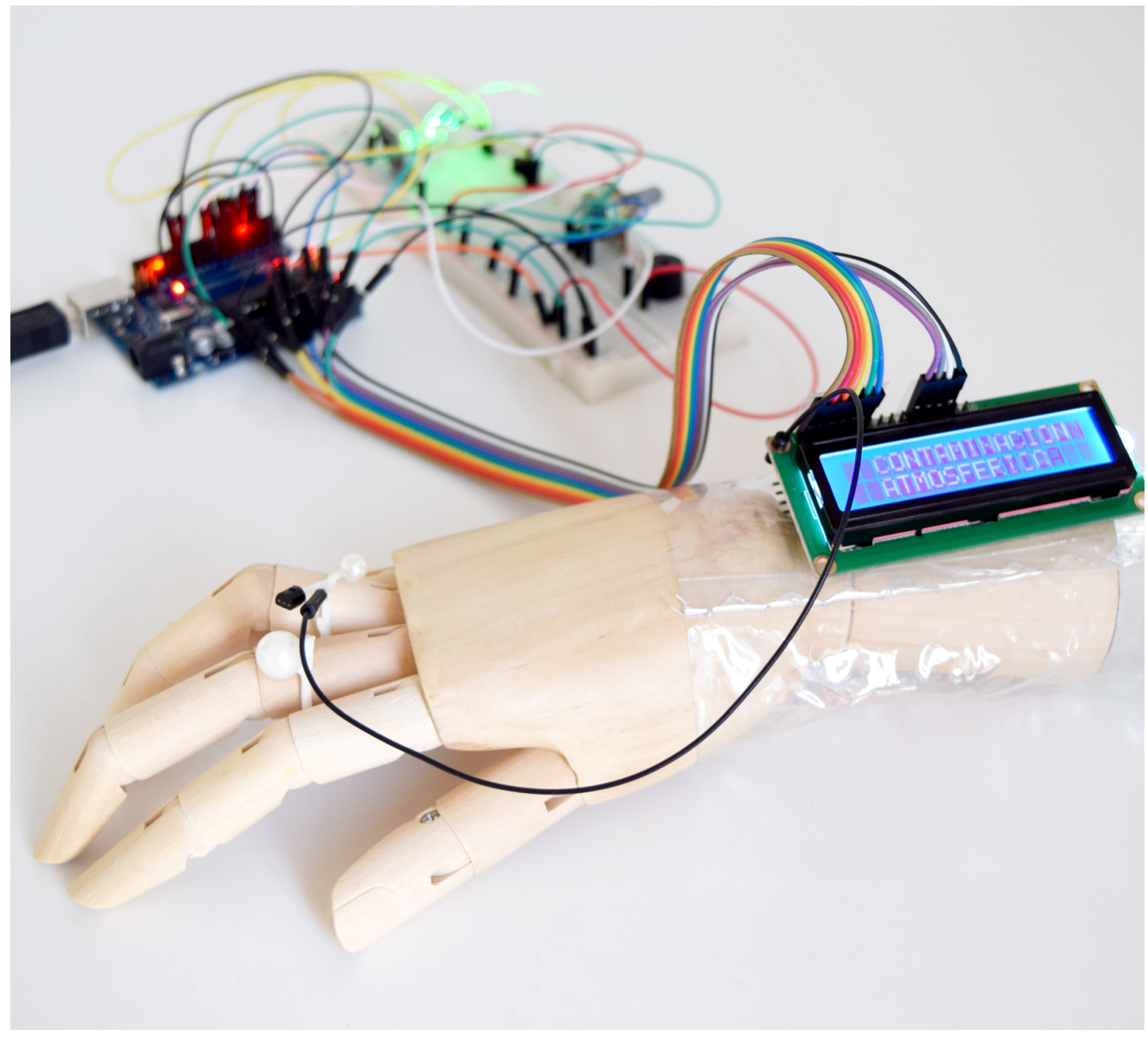

La joya medidora de $\mathrm{CO} 2$ en un dispositivo tecnoafectivo diseńado para comunicarse con La Mujer Digital y avisarle del momento en el que la contaminación atmosférica es peligrosa, esto es, cuando las partículas en suspensión PM2,5(diámetros inferiores a 2,5um)superan los 300 microgramos por metro cúbico (límite en el que comienza el valor de peligrosidad). wEl dispositivo está conformado por un anillo con un sensor de CO2 conectado a un circuito de arduino. Este circuito, conectado a una pantalla, se ha programado para que cuando alcance dicho límite aparezca en ella un mensaje escrito y un sonido de emergencia. El anillo es un dispositivo diseńado e impreso en $3 D$, en plástico tipo sbs. Se trata de una joya en forma de doble anillo que engarza varias piezas con detalles en aplicaciones en forma de perla, y un sensor de arduino.

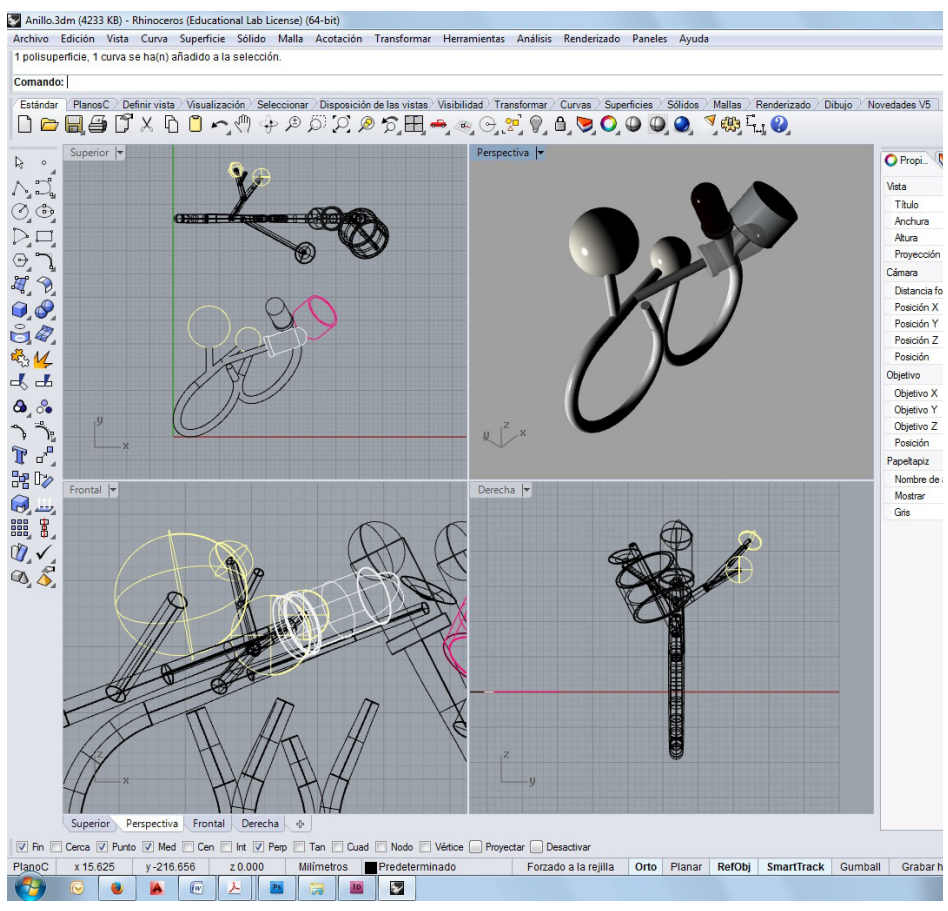




\begin{tabular}{|c|c|c|c|}
\hline 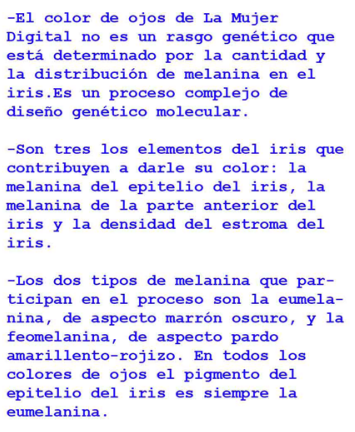 & 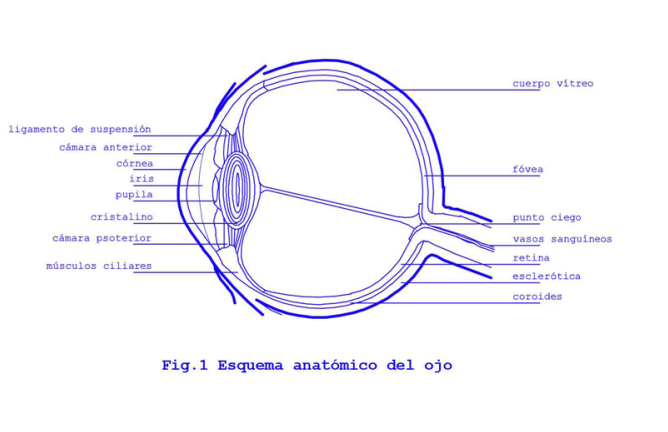 & 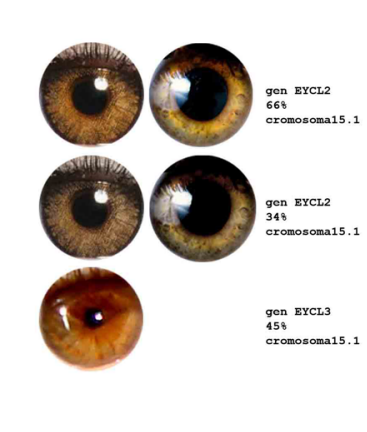 & 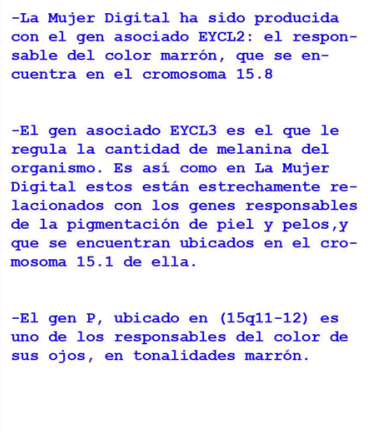 \\
\hline 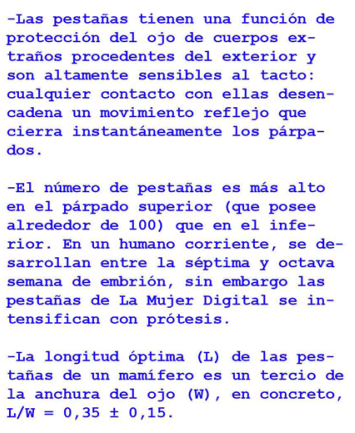 & $\begin{array}{c}\text { septas ofititat } \\
\text { Fig. } 2 \text { Esquema }\end{array}$ & $\gamma$ & 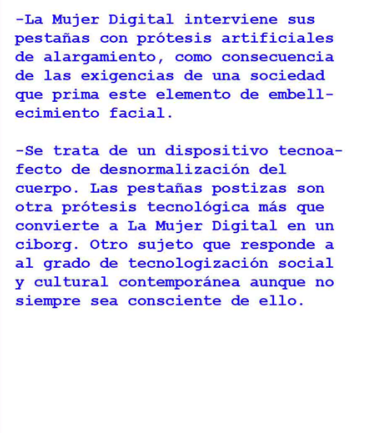 \\
\hline 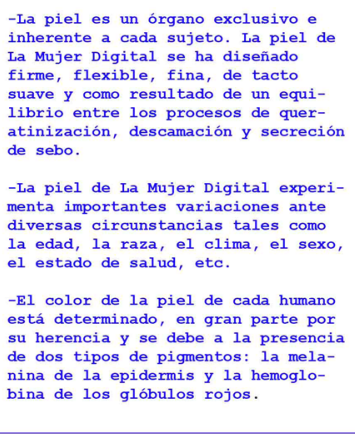 & 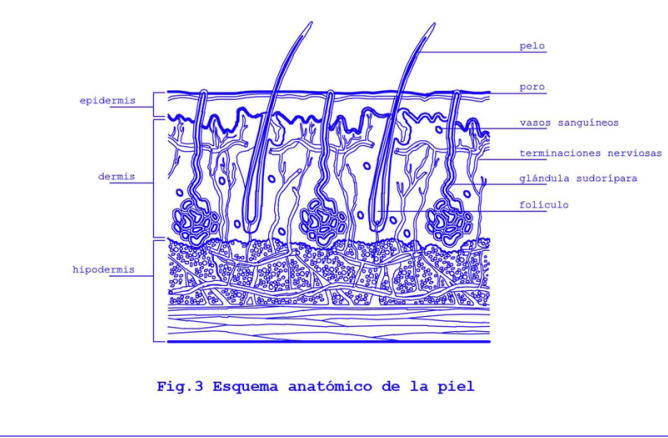 & pantone 8s & 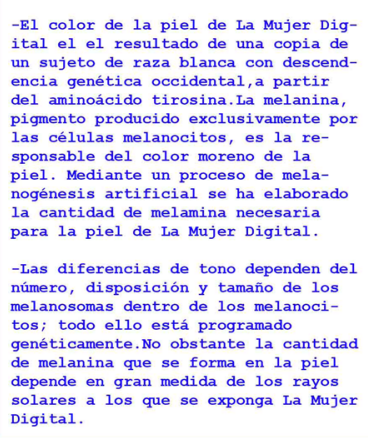 \\
\hline 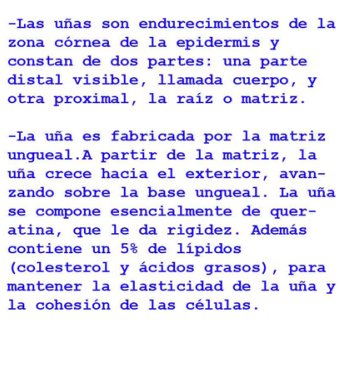 & Fig.5 Esquema anatómico de 1a uña & & 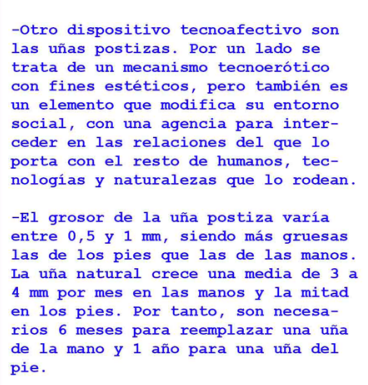 \\
\hline
\end{tabular}




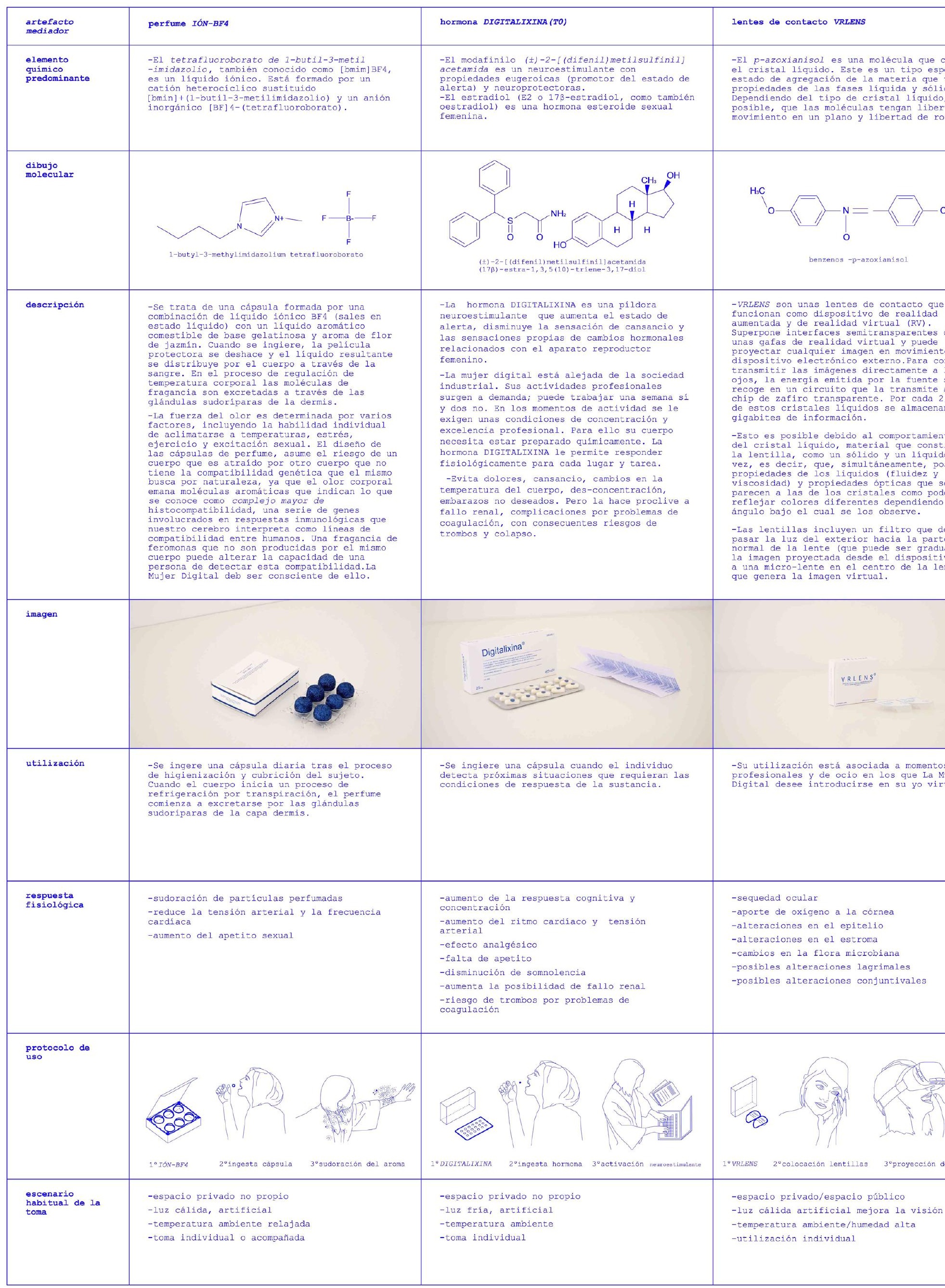




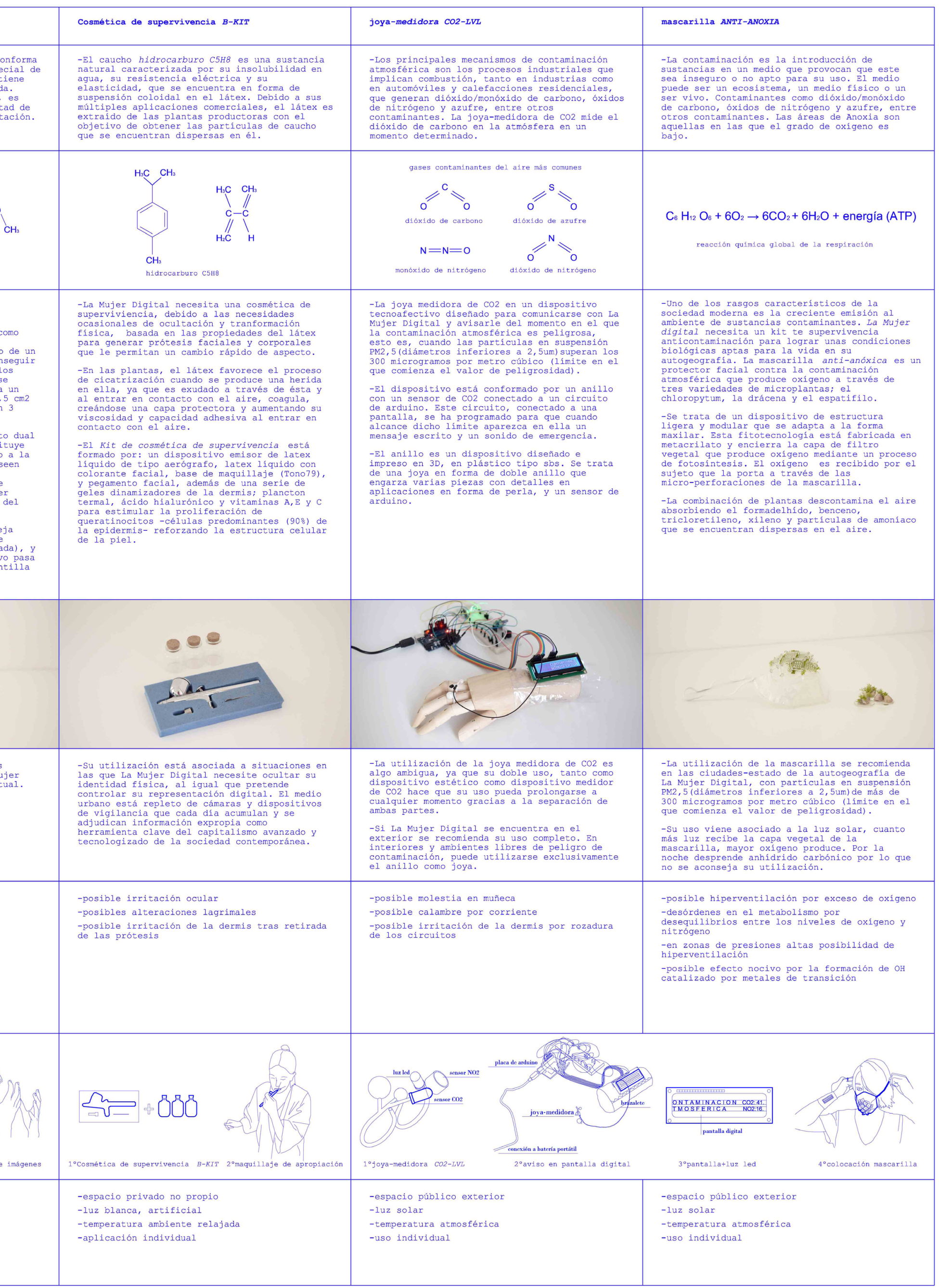



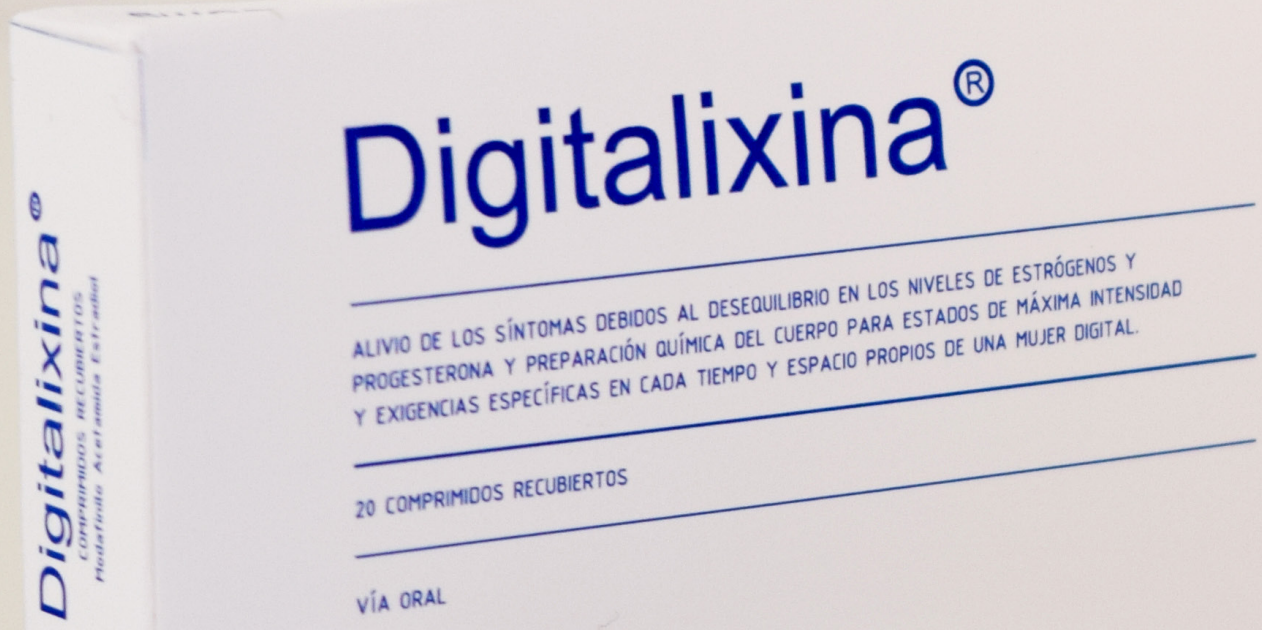

DEBIDOS AL DESEQUILIBRIO EN LOS NIVELES OE ES Ḿ́xima INTENSIOAD

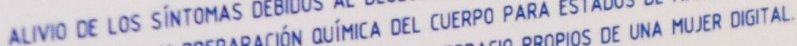

PROGESTERONA Y PREPARAC IN CADA TIEMPO Y ESPACIO PROPOS OE UNA YUER DILL

$Y$ EXIGENCIAS ESPECIFICAS EN CADA TIEMPO Y ESPR

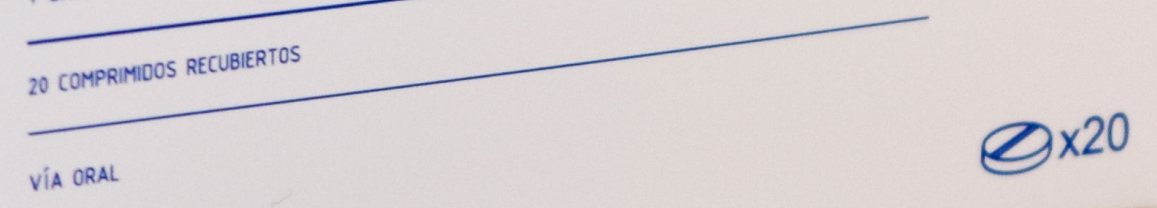

$25 \mathrm{mg}$ 
